\title{
Determining dissolved and biogenic silica
}

\section{Koistinen, Jaana}

Humana press

2020

Koistinen , J , Sjöblom , M \& Spilling , K 2020 , Determining dissolved and biogenic silica . in K Spilling (ed.), Biofuels from Algae : Methods and Protocols . vol. 1980 , Methods in Molecular Biology , Humana press , New York , pp. 95-101 . https://doi.org/10.1007/7651_2018_129

http://hdl.handle.net/10138/317335

https://doi.org/10.1007/7651_2018_129

cc_by

acceptedVersion

Downloaded from Helda, University of Helsinki institutional repository.

This is an electronic reprint of the original article.

This reprint may differ from the original in pagination and typographic detail.

Please cite the original version. 
Methods in Molecular biology (2020) 1980: 95-101

DOI 10.1007/7651_2018_129

\section{Determining dissolved and biogenic silica}

Jaana Koistinen $^{1}$, Mervi Sjöblom ${ }^{1}$, Kristian Spilling ${ }^{2}$

${ }^{1}$ Tvärminne Zoological Station, University of Helsinki, JA Palménin tie 260, 10900 Hanko, Finland

${ }^{2}$ Finnish Environment Institute, PO Box 140, 00251 Helsinki, Finland

Corresponding author:

Jaana Koistinen

Email: jaana.koistinen@helsinki.fi 


\begin{abstract}
Most algae do not use silicon in any form with one notable exception, diatoms. Silicon is a major constituents of diatoms. Diatoms are characterized by high growth rates and are often one of the key groups in forming algal blooms in natural waters, and as such it is an interesting group for cultivation. In this chapter we present methods for determining dissolved silica (DSi) and biogenic silica (BSi), oxide forms of silicon, based on colorimetric methods. BSi is determined after filtration and alkaline digestion.
\end{abstract}

Key words: biogenic silica, diatoms, dissolved silica, silicon

Running title: Determining dissolved and biogenic silica 


\section{Introduction}

Most algae do not use silicon (Si) in any form with one notable exception, diatoms in addition to some smaller groups such as silicoflagellates. Silicon, one of the most abundant elements on the surface of the earth, is a major constituent of diatoms and may become limiting for diatom growth. Silicon appears as the oxide (silica) or silicates, most of silicon being bound to rocks as silicate minerals. Chemical weathering brings dissolved silica (DSi), the form that it is available for diatoms. Diatoms are characterized by high growth rates and are often one of the key groups in forming algal blooms in natural waters, and as such it is an interesting group for cultivation [1,2]. Part of the success of the diatoms has been attributed to the fact that they have silicified cell walls, hydrated amorphous silica forming the outer cell wall, termed frustules (Fig. 1). The metabolic cost of producing silicified walls has been hypothesized to the lower than for building carbon based (e.g., cellulose) walls and provide the diatoms with the potentially very high (>1/d) maximum growth rate [3, 4].

The diatom frustules consists of two halves that that are joined in the middle similar to a box with a lid, where both the box and lid part is of equal size in most species. During cell division, both of the two halves becomes the lid part of the new cell. The old lid forms a new cell of equal size whereas the old box part (now the new lid) forms a slightly smaller cell. This leads to smaller average size of the population over time (several generations). When cells reach the smallest possible size, a spore known as an auxiospore forms. The auxiospore increases its size to the maximum for the species, and the process starts form the beginning again [5].

Measuring silicon is only necessary when cultivating diatoms, but then it is a critical to keep track of the silicon concentration. The need for silicon is often considered as 1:1 ratio with 
nitrogen (Redfield- Brzezinski ratio), but this is somewhat depending on the species in question. Many species are able to grow well also in water with $\mathrm{N}$ :Si ratio $>1$, and might have thinner frustules, which could be beneficial as silica frustules are hard to break. In order to determine the optimal nutrient ratio, it is important to also known the organic forms in the algal biomass, termed biogenic silica (BSi).

In this chapter we present a colorimetric method for determining dissolved silica (DSi), reactive silica (dissolved silicate, mono- and polymeric silica, silicic acid) [6], and a method for biogenic silica (BSi), based on the same principles. Silicon analysis is based on the molybdate-blue method [6]. Silicomolybdic acid is formed when sample in acid solution is treated with a molybdate solution, then the complex is reduced by ascorbic acid to blue complex. The determination of BSi includes filtration and wet-alkaline procedure, which converts BSi to silicic acid $\left(\mathrm{Si}(\mathrm{OH})_{4}\right)[7]$.

\section{Materials}

Use only plasticware (see Note 1) and analytical grade reagents.

\subsection{Dissolved silica}

1. Concentrated sulfuric acid $\left(96 \% \mathrm{H}_{2} \mathrm{SO}_{4}\right)$.

2. Ammonium molybdate tetrahydrate $\left(\left(\mathrm{NH}_{4}\right)_{6} \mathrm{Mo}_{7} \mathrm{O}_{24} \cdot 4 \mathrm{H}_{2} \mathrm{O}\right)$.

3. Oxalic acid dehydrate $\left((\mathrm{COOH})_{2} \cdot 2 \mathrm{H}_{2} \mathrm{O}\right)$.

4. Ascorbic acid $\left(\mathrm{C}_{6} \mathrm{H}_{8} \mathrm{O}_{6}\right)$.

5. Silicon standard $1000 \mathrm{mg}$ Si in $14 \%$ sodium hydroxide solution.

6. Ultrapure water (e.g., Milli-Q).

7. 50-100 ml polypropylene graduated cylinders. 
8. 50-1000 $\mathrm{ml}$ polypropylene volumetric flasks.

9. 100-1000 $\mathrm{ml}$ polypropylene storage bottles.

10. Spatulas.

11. Adjustable pipette and pipette tips.

12. $50 \mathrm{ml}$ polypropylene reaction flasks.

13. Analytical balance.

14. Refrigerator.

15. Spectrophotometer.

16. $1 \mathrm{~cm}$ plastic cuvette.

\subsection{Biogenic silica}

1. Polycarbonate filters (e.g., $0.8 \mu \mathrm{m}$ Nuclepore $\emptyset 2.5 \mathrm{~cm}$ ).

2. Vacuum filtration device (see Note 1).

3. Vacuum pump.

4. 50-100 ml polypropylene graduated cylinders.

5. 50-1000 ml polypropylene volumetric flasks.

6. 100-1000 $\mathrm{ml}$ polypropylene storage bottles.

7. Spatulas.

8. Adjustable pipette and pipette tips.

9. $50 \mathrm{ml}$ polypropylene bottles or centrifuge tubes with screw caps.

10. Sodium Hydroxide $(\mathrm{NaOH})$.

11. Concentrated hydrochloric acid $(37 \% \mathrm{HCl})$.

12. Concentrated sulfuric acid $\left(96 \% \mathrm{H}_{2} \mathrm{SO}_{4}\right)$.

13. Ammonium molybdate tetrahydrate $\left(\left(\mathrm{NH}_{4}\right)_{6} \mathrm{Mo}_{7} \mathrm{O}_{24} \cdot 4 \mathrm{H}_{2} \mathrm{O}\right)$.

14. Oxalic acid dihydrate $\left((\mathrm{COOH})_{2} \cdot 2 \mathrm{H}_{2} \mathrm{O}\right)$. 
15. Ascorbic acid $\left(\mathrm{C}_{6} \mathrm{H}_{8} \mathrm{O}_{6}\right)$.

16. Ultra-pure water (e.g., Milli-Q water).

17. Analytical balance.

18. Refrigerator.

19. Water bath $\left(100{ }^{\circ} \mathrm{C}\right)$.

20. Spectrophotometer.

$21.1 \mathrm{~cm}$ plastic cuvette.

\section{Methods}

Use acid-washed plastic plasticware (soaked for $4 \mathrm{~h}$ in $6 \% \mathrm{HCl}$ and rinsed with deionized water).

\subsection{Dissolved silica}

The procedure follows that of Koroleff in the first edition of [6] and [8].

1. Prepare $3.6 \mathrm{~mol} / \mathrm{l}$ sulfuric acid solution. Carefully add $10 \mathrm{ml}$ concentrated acid to 37 $\mathrm{ml}$ ultrapure water in a plastic beaker (see Note 2), cool and make up to $50 \mathrm{ml}$ with ultrapure water in a volumetric flask.

2. Prepare molybdate solution by dissolving $10 \mathrm{~g}$ ammonium molybdate tetrahydrate in $40 \mathrm{ml}$ ultrapure water slightly heating, and then add ultrapure water to a final volume of $50 \mathrm{ml}$.

3. Prepare Reagent I by adding $50 \mathrm{ml}$ of the ammonium molybdate tetrahydrate solution (see step 2) to $50 \mathrm{ml} 3.6 \mathrm{~mol} / \mathrm{l}$ sulfuric acid solution (see Note 3 ). Store in a polyethylene bottle at room temperature. 
4. Prepare Reagent II by dissolving $8.8 \mathrm{~g}$ oxalic acid in $90 \mathrm{ml}$ ultrapure water and then add ultrapure water to a final volume of $100 \mathrm{ml}$. Store in a polyethylene bottle at room temperature.

5. Prepare Reagent III by dissolving $1.8 \mathrm{~g}$ ascorbic acid in $100 \mathrm{ml}$ ultrapure water. Store in a polyethylene bottle in a refrigerator (usable as long as colorless) protected from light.

6. Prepare standard solution $1000 \mathrm{mg} \mathrm{Si} / \mathrm{l}$ by diluting Silicon standard with ultrapure water to a final volume of $1000 \mathrm{ml}$. Store in a polyethylene bottle at room temperature

7. On the day of analysis, prepare suitable working solutions of silicate $(0-1000 \mu \mathrm{g} \mathrm{Si} / \mathrm{l})$ for calibration by diluting the standard stock solution (see step 6) with ultrapure water.

8. Prepare analyzer for analyses according to the operation manual (see Note 4). Dilute the reagents 1:10 for analyzer.

9. Place standards in the autosampler of an analyzer or measure the standards manually by a spectrophotometer for a calibration curve and linearity test (see Note 5).

10. For manual analyses, measure three $35 \mathrm{ml}$ portions of working standard and three 35 $\mathrm{ml}$ portions of ultrapure water for blanks with graduated cylinder to reaction flasks.

11. Add $1 \mathrm{ml}$ of Reagent I to $35 \mathrm{ml}$ standards and blanks, wait for $10 \mathrm{~min}$, and then add 1 $\mathrm{ml}$ each of Reagents II and III and wait for $30 \mathrm{~min}$ (mix gently after each addition).

12. Measure the absorbance of standards and blanks in a $1 \mathrm{~cm}$ cuvette at $810 \mathrm{~nm}$ for a calibration curve (see Note 5).

13. Collect the samples in polyethylene bottles and analyze the samples immediately after collection. The sample can be stored in a plastic bottle in a refrigerator for about one day. 
14. Place samples in the autosampler of an analyzer or perform manual analyses with a spectrophotometer. Verify proper operation of the instrument with certified reference material and include ultrapure water blanks in the run (see Note 6).

15. For manual analyses, measure $35 \mathrm{ml}$ of the sample with a graduated cylinder.

16. Add $1 \mathrm{ml}$ of Reagent I, wait for $10 \mathrm{~min}$, and then add $1 \mathrm{ml}$ each of Reagents II and III and wait for $30 \mathrm{~min}$ (mix gently after each addition).

17. Measure the absorbance of samples in a $1 \mathrm{~cm}$ cuvette at $810 \mathrm{~nm}$ (if the absorbance is greater than that of the highest standard, prepare diluted sample) and calculate the silicon concentration by the calibration curve (see Note 7).

\subsection{Biogenic Silica}

1. Place the polycarbonate filter in the filtration device and apply suction with the vacuum pump.

2. Pipette a known volume of culture through the filter (see Note 8).

3. Remove filter and place in a plastic screw-capped plastic bottle.

4. Let the filter dry and store at room temperature in a desiccator until determination of BSi.

5. Place a clean filter into a vial for laboratory blank (Note 9).

6. Prepare $3.6 \mathrm{~mol} / \mathrm{l}$ sulfuric acid solution (see Sect. 3.1, step 1).

7. Prepare molybdate solution (see Sect. 3.1, step 2).

8. Prepare Reagent I (see Sect 3.1, step 3).

9. Prepare Reagent II (see Sect. 3.1, step 4).

10. Prepare Reagent III (see Sect. 3.1, step 5).

11. Prepare standard solution $1000 \mathrm{mg} \mathrm{Si/1} \mathrm{(see} \mathrm{Sect.} \mathrm{3.1,} \mathrm{step} \mathrm{6).}$ 
12. Prepare $0.2 \mathrm{~mol} / \mathrm{l}$ sodium hydroxide solution by dissolving $8 \mathrm{~g} \mathrm{NaOH}$ in $1000 \mathrm{ml}$ ultrapure water. Store in polyethylene bottle at room temperature.

13. Prepare $0.2 \mathrm{~mol} / \mathrm{l}$ hydrochloric acid solution. Carefully add $16 \mathrm{ml}$ concentrated $\mathrm{HCl}$ to $500 \mathrm{ml}$ of ultrapure water (see Note 2), cool and make up to $1000 \mathrm{ml}$ with ultrapure water. Store in a polyethylene bottle at room temperature.

14. At the time of the measurements, prepare suitable working solutions of silicon (0$1000 \mu \mathrm{g} \mathrm{Si} / \mathrm{l}$ ) for calibration by diluting the standard stock solution (see step 11) with ultrapure water.

15. Pipette calibration solution in a plastic screw-capped plastic bottle.

16. Pipette $10 \mathrm{ml} 0.2 \mathrm{~mol} / \mathrm{l} \mathrm{NaOH}$ to the vial and close the cap loosely.

17. Place in water bath at $100{ }^{\circ} \mathrm{C}$ for $15 \mathrm{~min}$ and then cool to room temperature.

18. Add $10 \mathrm{ml} 0.2 \mathrm{~mol} / \mathrm{l} \mathrm{HCl}$, close the cap, and mix by swirling.

19. Prepare analyzer for analyses according to the operation manual (see Note 4). Dilute the reagents 1:10 for analyzer.

20. Place standards in the autosampler of an analyzer or measure the standards manually by a spectrophotometer for a calibration curve and linearity test (see Note 5).

21. For manual analyses, add $600 \mu \mathrm{l}$ Reagent I, wait for $10 \mathrm{~min}$ and then add $600 \mu \mathrm{l}$ each of Reagents II and III and wait for 30 min (mix gently after each addition).

22. Measure the absorbance of standards and blanks in a $1 \mathrm{~cm}$ cuvette at $810 \mathrm{~nm}$ for a calibration curve and linearity test (see Note 5).

23. When measuring samples, start by adding $10 \mathrm{ml} 0.2 \mathrm{~mol} / \mathrm{l} \mathrm{NaOH}$ and close the cap loosely.

24. Place in water bath at $100{ }^{\circ} \mathrm{C}$ for $15 \mathrm{~min}$ and then cool to room temperature.

25. Add $10 \mathrm{ml} 0.2 \mathrm{~mol} / 1 \mathrm{HCl}$, close the cap, and mix by swirling. 
26. Place samples in the autosampler of an analyzer or perform manual analyses with a spectrophotometer. Verify proper operation of the instrument with certified reference material and include ultrapure water blanks in the run (see Note 6).

27. For manual analyses, add $600 \mu \mathrm{l}$ Reagent I, wait for $10 \mathrm{~min}$ and then add $600 \mu \mathrm{l}$ each of Reagents II and III and wait for 30 min (mix gently after each addition).

28. Measure the absorbance of samples in a $1 \mathrm{~cm}$ cuvette at $810 \mathrm{~nm}$ (if the absorbance is greater than that of the highest standard, prepare diluted sample) and calculate the silicon concentration by the calibration curve (see Note 7).

\section{Notes}

1. Glass contains silica and samples/standards should not allowed to come into contact with glass to avoid contamination.

2. Do this very carefully as a lot of heat is produced in this process.

3. Pour carefully the ammonium molybdate tetrahydrate solution to the acid solution, otherwise the solution turns white, milky looking, and cannot be used.

4. It is critical to have proper training before running the analyzer. This will depend on the system that you are using and it is beyond the scope of this chapter to go into the details of the operation of the instrument. We have used Thermo Scientific Aquakem 250 analyser for silica.

5. Calibration curve is prepared by plotting measured absorbance of standards versus standard concentrations (linear regression).

6. Start each sample run with blank(s) and reference material to verify proper operation of the instrument. Analyze samples in sequences of max 20 samples followed by a 
blank and reference material. Insert also standards in the sequence to to test accuracy and drift during the analytical runs.

7. Determine concentration in the sample by the slope of the calibration curve. Reduce the absorbance of the blank from the absorbance of the sample.

8. The method is very sensitive; so for diatom cultures you should use a relatively little volume, just enough to see some color on the filter.

9. At least one for each batch of samples to assess and correct for laboratory contamination.

\section{References}

[1] Hildebrand, M., Davis, A. K., Smith, S. R., Traller, J. C., \& Abbriano, R. (2012). The place of diatoms in the biofuels industry. Biofuels, 3(2), 221-240.

[2] Bozarth, A., Maier, U. G., \& Zauner, S. (2009). Diatoms in biotechnology: modern tools and applications. Applied microbiology and biotechnology, 82(2), 195-201.

[3] Armbrust EV (2009) The life of diatoms in the world's oceans. Nature 459: 185-192.

[4] Martin-Jézéquel V, Hildebrand M, Brzezinski MA (2000) Silicon metabolism in diatoms: implications for growth. J Phycol 36: 821-840.

[5] Round FE, Crawford RM, Mann DG (2007) Diatoms: biology and morphology of the genera. Cambridge University Press, Cambridge.

[6] Grasshoff K, Ehrhardt M, Kremling K (1999) Methods of seawater analysis. Wiley-VCH Verlag Gmbh, Weinheim.

[7] Krausse GL, Schelske CL, Davis CO (1983) Comparisons of three wet-alkaline methods of digestion of biogenic silica in water. Freshw Biol 13: 73-81.[8] Koroleff F (1979) Methods for the chemical analysis for seawater. Meri 7: 1-60 (in Finnish). 
[8] Koroleff F (1979) Methods for the chemical analysis for seawater. Meri 7:1-60 (in Finnish).

[9] Haeckel EHPA (1904) Kunstformen der Natur. Bibliographisches Institut, Leipzig. 


\section{Figure captions}

Fig 1. Two examples of diatom frustules: Navicula bullata left and Triceratium robertsianum right [9]. This work is in the public domain.

Fig.1

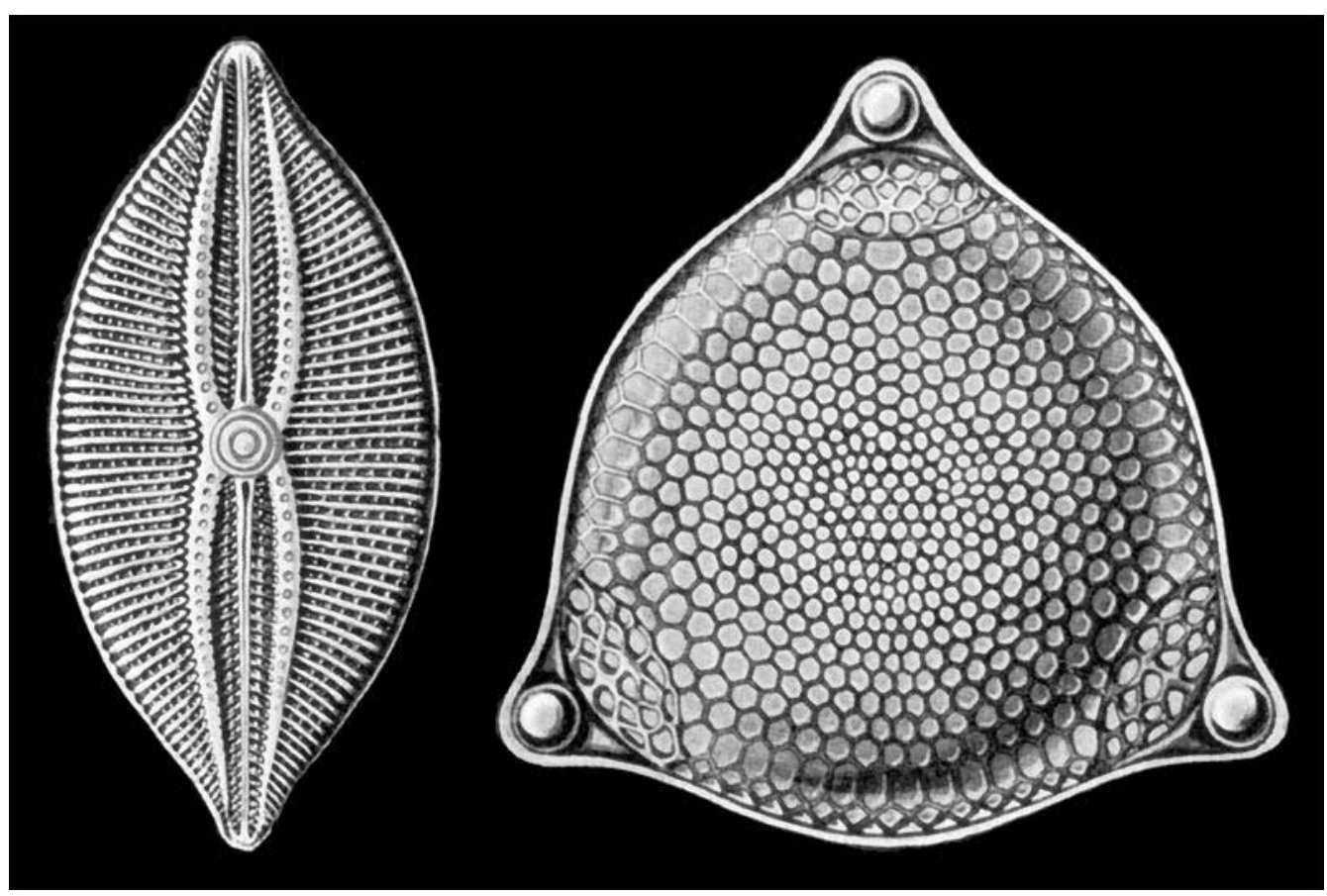

